\title{
Analysis of the mixing processes in the subtropical Advancetown Lake, Australia
}

\author{
Edoardo Bertone*, Rodney A. Stewart ${ }^{\star}$, Hong Zhang ${ }^{* 1}$ and Kelvin O'Halloran ${ }^{\#}$ \\ *Griffith School of Engineering, Griffith University, Gold Coast Campus, QLD 4222, Australia.

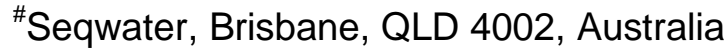

Submitted to Journal of Hydrology, February, 2014

Revised Version 1 submitted, May 2014

Revised Version 2 submitted, September 2014

Revised Version 3 submitted, November 2014

${ }^{1}$ Author to whom all correspondence should be addressed: ${ }^{1}$ Griffith School of Engineering, Griffith University, Gold Coast Campus, QLD 4222, Australia. Tel.: +61 75552 9015; Fax: +61 75552 8065. Email: hong.zhang@griffith.edu.au 


\section{Abstract}

This paper presents an extensive investigation of the mixing processes occurring in the subtropical monomictic Advancetown Lake, which is the main water body supplying the Gold Coast City in Australia. Meteorological, chemical and physical data were collected from weather stations, laboratory analysis of grab samples and an in-situ Vertical Profiling System (VPS), for the period 2008-2012. This comprehensive, high frequency dataset was utilised to develop a one-dimensional model of the vertical transport and mixing processes occurring along the water column. Multivariate analysis revealed that air temperature and rain forecasts enabled a reliable prediction of the strength of the lake stratification. Vertical diffusion is the main process driving vertical mixing, particularly during winter circulation. However, a high reservoir volume and warm winters can limit the degree of winter mixing, causing only partial circulation to occur, as was the case in 2013. This research study provides a comprehensive approach for understanding and predicting mixing processes for similar lakes, whenever high-frequency data are available from VPS or other autonomous water monitoring systems.

Keywords: lake dynamics; vertical profiling system; transport processes; mixing processes

\section{Introduction}

Continuously monitoring and understanding the physical and biogeochemical cycles of lakes or reservoirs used for drinking water purposes is vital for water suppliers. A limited understanding of these cycles often leads to inadequate management practices and an increased prevalence of raw water sourced from surface waters failing to meet drinking water standards with conventional treatment, which in turn significantly diminishes the confidence of the community in the water service provider.

Typically, the most important physical and chemical parameters of a water storage reservoir are monitored on a regular basis. However, these data are often collected and stored without any 
consideration for its decision-making purposes, thereby adding little value (Zaw and Chiswell, 1999); poor data collection techniques and organization are typically recognised as being the main causes of inefficient reservoir management (Mohan et al., 1996). Hence, there should be more strategic consideration of the use of collected and stored data for the purpose of gaining a complete understanding of the physical and chemical processes of the reservoir.

The most important parameters currently monitored, to which many other chemical and physical processes are related, are water temperature, dissolved oxygen and $\mathrm{pH}$. More specifically, the chemical processes and the activities of organisms in a lake are both highly dependent on the seasonal thermal cycle of the lake (Dodds, 2002). For subtropical lakes, the temperature is always relatively high and no layer in the water column will ever drop below $4^{\circ} \mathrm{C}$. In these lakes, the water column is usually thermally and chemically stratified for most of the summer, spring and even autumn with a warmer, oxygen-rich surface layer called the epilimnion and a colder, oxygen-poor bottom layer called hypolimnion (Tundisi and Matsumura, 2011). Solar radiation causing heating of the surface waters of the lake and photosynthesis is the key driver of both thermal and chemical stratification processes. Photosynthesis also aids the removal of acidic $\mathrm{CO}_{2}$ forms such as $\mathrm{HCO}_{3}{ }^{-}$ resulting in a more alkaline $\mathrm{pH}$ level in the epilimnion. In the deeper, more acidic hypolimnion, the photosynthesis does not occur and the oxygen is depleted through microbial oxidation of organic matter (Bertoni, 2011) or bacteria respiration and denitrification activities (Socolofsky and Jirka, 2004; Tundisi and Matsumura, 2011). Such a reducing, hypoxic environment is typically rich in nutrients, mainly because of precipitation from the epilimnion (Hulth et al., 1999) or flux from the sediments (Fisher et al. 2005). Under stratified conditions, the water of the epilimnion and the hypolimnion are well separated by the transition layer, called metalimnion, and the level of nutrients in the epilimnion is low. However, turbulent events such as rainfall or strong winds can create mixing and bring high nutrients loads to the surface waters. In particular, strong and persistent wind events, coupled with a long fetch, induce internal and surface seiches (Bertoni, 2011) and even sediment re-suspension (Abesser and Robinson, 2010). These events are magnified during winter, when the gradient of water temperature drops along with the solar 
radiation and air temperature; colder, denser water plumes precipitate from the epilimnion downwards towards the hypolimnion (Bednarz et al., 2011). Strong winds can accelerate this mixing process (Zhang and Chan, 2003). Ultimately, the difference in the water temperature at all levels in the water column approaches zero and the lake destratification occurs. Subtropical lakes and reservoirs destratifying once per year during winter are called warm monomictic, while if they only partially mix they are called meromictic (Tundisi and Matsumura, 2011). During the period of destratification, the water is well mixed vertically with most of its chemical and biological constituents typically having similar concentrations throughout the entire water column (Nürnberg, 1988). Understanding the mixing processes leading to stratification or destratification is crucial for water suppliers as certain water constituents (e.g. manganese) in the epilimnion, where the water is drawn from, can fluctuate significantly in this period, making it more challenging for treatment plant operators to ensure that this water can achieve drinking water guidelines before being distributed.

Because of the importance of these phenomena, several studies have been completed. Elçi (2008) investigated the structure of thermal stratification and its effects on the water quality of a Turkish reservoir, focusing on the dissolved oxygen and turbidity variations. This study had a comprehensive dataset of field measurements that enabled a deep understanding of the relationships between meteorological factors and water quality parameters through a series of nondimensional indexes and multivariate analysis. The results indicated how air temperature and lateral flows affect the dissolved oxygen concentrations, while rain and wind mostly influence the turbidity levels. Tuan et al. (2009) explored water mixing in a shallow Japanese lake. Their study utilised non-dimensional "stratification strength" indexes, basic statistical analysis and heat exchange equations to model the water mixing process. In such a shallow lake, the diurnal stratification was mostly affected by wind action, with thermal heating playing a minor role during strong wind events. In cases where the lake has high horizontal velocities, three-dimensional numerical models derived by multiple data collection points in the reservoir are often necessary (Akitomo et al., 2004; Akitomo et al., 2009; Kitazawa, 2012). However, where horizontal velocities 
are relatively slow, a one-dimensional analysis can provide reliable results, and are often preferable when the water quality problem being examined is near the location of the data collection system as was the case in this study.

In the present study, the research location is Advancetown Lake, which supplies most of the water to Gold Coast City in Queensland, Australia. Large amounts of in-situ Vertical Profiling System (VPS) data were collected approximately $150 \mathrm{~m}$ from the dam wall (indicated in red in Figure 1) since 2008 at a 3 hourly recording interval. Additionally, grab samplings were collected and analysed on a weekly basis. Because of the features of the data, which were collected continuously at various depths at the same location, the mixing dynamics of a one-dimensional vertical profile could be created. Applying the more commonly implemented VPS technology and associated streamed data to model the mixing dynamics of such a sub-tropical reservoir has not yet been presented in the literature.

Advancetown Lake present similar depth and inflows characteristics of other reservoirs where onedimensional models were applied assuming horizontal homogeneity (see e.g. Helfer et al. 2011); hence, VPS data can be appropriately inputted into one-dimensional time-dependent dynamic equations in order to calculate vertical velocities and diffusivity coefficients. The high frequency (3 hours) of the VPS data guarantees stability to such a numerical model, which could not have been implemented in cases where only traditional lower-frequency sampling data are available. Moreover, VPS data also enables further analysis of intra-daily mixing processes, such as nighttime mixing during winter or surface wind mixing during summer. Furthermore, multivariate and non-dimensional analyses were performed using algorithms that were able to automatically calculate the extent of correlation between different variables. Ultimately, a one-dimensional study of internal waves was included too. The proposed methodology aims to make the most of this form of collected data (i.e. high-frequency one-dimensional data) for reservoirs of similar characteristics (i.e. medium-size, relatively deep, subtropical) in order to provide a better understanding of the causes and effects of the mixing processes affecting similar lakes. 


\section{Methodology}

\section{$\underline{2.1 \text { Research domain }}$}

Advancetown Lake $\left(153.28^{\circ} \mathrm{E}, 28.05^{\circ} \mathrm{S}\right.$, Figure 1), also known as Hinze Dam since the lake was dammed, supplies most of the water to Gold Coast City (Queensland, Australia), which has a population of around 500,000 inhabitants. The dam was originally constructed in $1976(42,400 \mathrm{ML}$ water storage capacity), upgraded in 1989 (161,070 ML) and again in 2011. In the most recent upgrade the dam wall was raised a further 15 metres (from 93.5 to $108 \mathrm{~m}$ ), doubling the capacity of the reservoir $(310,730 \mathrm{ML})$ and providing increased water security and flood mitigation. Figure 2 shows the stored volume in the reservoir from 1985 to 2013. After the 2011 upgrade, the surface area increased from $9.72 \mathrm{~km}^{2}$ to $15 \mathrm{~km}^{2}$, while the catchment area covers $207 \mathrm{~km}^{2}$ including the Numinbah Valley and Springbrook Plateau and is mostly contained within state forests and national parks. The two main inflows are the Nerang River and the Little Nerang Creek, which also represents the outflow of a smaller dam, Little Nerang. The average residence time, calculated as the ratio between the reservoirs' volume and the average inflow to the dam, was 920 days prior to the upgrade of the dam, but with the recent doubling of the reservoir capacity, this retention time also doubled (1775 days) since the reservoir reached its full capacity during the 2013 summer wet season, and the average flow did not change. An intake tower with gates every 5 metres, located next to the dam wall, draws the water from the most convenient depth, redirecting it to the closest treatment plant, situated $10 \mathrm{~km}$ northeast of the reservoir. The water treatment and distribution from Advancetown Lake are managed by Seqwater, which is the main bulk water supplier in South-East Queensland.

Presently, water quality is primarily monitored through laboratory analysis of manual water samplings on a weekly basis. Also, since 2008 an in-situ Vertical Profiling System (VPS) was installed. This VPS consists of a YSI Sonde suspended by a cable to a floating buoy which is automatically winched up and down the water column and collects water quality parameters such as water temperature, dissolved oxygen, $\mathrm{pH}$, conductivity, redox potential and turbidity. Collected 
data are transmitted via telemetry for the whole profile every 3 hours. The VPS location, which is positioned near the intake tower (see point $A$ in Figure 1), is also near the location of the weekly water samplings; although the average depth of the reservoir is 32 metres, the sampling site is more than 50 metres deep.

Through an effective collaboration with Seqwater, historical data from Advancetown Lake were made available, mainly from weekly manual water samplings and from the VPS. The data were typically collected close to the lower intake tower of the reservoir. Data from the manual samplings cover the period 2000-2013, while the VPS was installed in 2008. For the sake of consistency, this paper focuses on the aligned manual and VPS data for the 2008 to 2013 period. Weather conditions for Advancetown Lake were collected from 2000 to 2011 from the Australian Bureau of Meteorology (BoM) (air temperature, solar radiation, rainfall, wind speed and direction, cloud cover). However, a weather station connected to the VPS provides air temperature and wind data every 3 hours since 2008. River inflow data were obtained from the Department of Energy and Resources Management of the Queensland Government (DERM).

\subsection{Data statistical analysis}

The VPS data were pre-processed and analysed by filtering and sorting: that is, algorithms were created in order to extract, from the raw database, data under a time series format. Subsequently, it was possible to detect trends and seasonal or daily variations. Also, statistical tests were performed to detect nonlinearities, such as the BDS test (see Brock et al., 1996), and nonnormalities, such as the Jarque-Bera (Jarque and Bera, 1987) and the Lilliefors test (Lilliefors, 1967). Multivariate analysis was performed to find the highest correlation coefficient between each pair of variables, by optimizing the lag (i.e. the delay from time $t$ ) and the span (i.e. the number of time steps) of the moving average. Specifically, an algorithm was implemented for performing a multilinear regression analysis between all the possible pairs $(X(t), Y(t))$ within an analysed time series by calculating: 


$$
R_{p, k, m, j, n}=\frac{\operatorname{cov}\left(X_{p, k, m}, Y_{p, j, n}\right)}{\sigma_{X_{p, k, m}} \sigma_{Y_{p, j, n}}}
$$

where $X_{p, k, m}=\frac{\sum_{i=0}^{m} X(p-k-i)}{m}$ and $Y_{p, j, n}=\frac{\sum_{i=0}^{n} Y(p-j-i)}{n} ; p$ is the time index for data $X$ and $Y ; k$ and $j$ are indexes representing the lag at which the times series are considered; $m$ and $n$ are indexes representing the span of the moving average considered; $\operatorname{cov}\left(X_{p, k, m}, Y_{p, j, n}\right)$ is the covariance between $X_{p, k, m}$ and $Y_{t p j, n} ; \quad \sigma_{X_{p, k, m}}$ and $\sigma_{Y_{p, j, n}}$ are the standard deviations of $X_{p, k, m}$ and $Y_{p, j, n}$.

Moreover, scatter plots of each variable against another enabled a visual interpretation of any linear and nonlinear trends that may have been present. All of these analyses helped in understanding the causal relationships between the physical / chemical variables of the reservoir and thus enlightened a clearer picture of the dams' mixing processes.

\section{$\underline{2.3 \text { Lake mixing dynamics }}$}

One-dimensional hydrodynamic models have been widely used in lake studies, assuming that the water bodies comply with the one-dimensional approximation in that the destabilizing forces variables (wind, surface heating and plunging inflows) do not act over prolonged periods of time (Imberger and Patterson, 1981; Han et al., 2000; Gal et al., 2003; Helfer et al. 2011). Typically, the models predict the vertical distribution of temperatures, salinity and density in lakes and reservoirs by using empirical or published diffusion coefficient. However, in the present study in Advancetown Lake, the hourly vertical profiles of temperature, salinity and density have been continuously collected for 5 years. All VPS data, therefore, can be applied to calculate the mixing coefficients in a one-dimensional model assuming the one-dimensional approximation is valid.

The continuity to be satisfied for the 1D model is as the following:

$$
\frac{\partial \rho(t, z)}{\partial t}+\frac{1}{A(z)} \frac{\partial(\rho(t, z) w(t, z) A(z))}{\partial z}=0
$$

with $\rho(t, z)$ and $w(t, z)$ being the water density and the vertical velocity at depth $z$ and time $t ; A(z)$ is the lake cross-section at depth $z$ which is assumed to change over depth, but not over time. In 
the present study, the VPS collected the temperature and conductivity in the water column; therefore the water density can be calculated through an empirical relationship, as in Millero and Poisson (1981):

$$
\rho=\rho_{0}+A \cdot S+B \cdot S^{3 / 2}+C \cdot S^{2}
$$

where $\rho$ is the density of the water $\left[\mathrm{kg} / \mathrm{m}^{3}\right] ; \rho_{0}$ is the density of pure water, function of the water temperature $\left[\mathrm{kg} / \mathrm{m}^{3}\right] ; S$ is the salinity of the water $[\mathrm{psu}]$, which can be calculated as a function of conductivity, and $A, B$ and $C$ are coefficients that are functions of the water temperature.

The simplified advection-diffusion equation for heat transport can be written as:

$$
\frac{\partial T(t, z)}{\partial t}=\frac{1}{A(z)} \frac{\partial}{\partial z}\left(A(z) D(t, z) \frac{\partial T(t, z)}{\partial z}\right)-\frac{w(t, z)}{A(z)} \frac{\partial(A(z) T(t, z))}{\partial z}+\frac{1}{A(z) C_{w}} \frac{\partial(A(z) H(t, z))}{\partial z}
$$

where $T(t, z)$ is the water temperature at depth $z$ and time $t ; D(t, z)$ is the vertical diffusivity at depth $z$ at time $t$; $A$ is the lake cross-section at depth $z ; H(t, z)$ is the heat source term due to heat exchange with the atmosphere (the heat exchange of inflow and outflow is ignored) and $C_{w}$ is volumetric heat capacity of water . Equation (2) can be discretised as:

$$
\frac{\rho_{i}^{n+1}-\rho_{i}^{n}}{\Delta t}+\frac{1}{A_{i}} \frac{\rho_{i+1}^{n} w_{i+1}^{n} A_{i+1}-\rho_{i}^{n} w_{i}^{n} A_{i}}{\Delta z}=0
$$

where the superscript $n$ is an index for time and subscript $i$ is an index for depth $(i=1$ is the bottom depth); $\Delta z$ is the distance between two adjacent layers, $\Delta t$ is the time step, $A_{i}$ is the cross-sectional area of layer $i$. With the boundary condition that $w_{1}^{n}=0, w_{i+1}^{n}$ can be calculated by using Equation (5). The water column was discretised with $\Delta z=1 \mathrm{~m}$.and a time step of $\Delta t=3600 \mathrm{~s}$.

The advection term in Equation (4) can be discretised as:

$$
\frac{w(t, z)}{A(z)} \frac{\partial(A(z) T(t, z))}{\partial z}=\frac{1}{2}\left(\frac{w_{i}^{n}-\left|w_{i}^{n}\right|}{A_{i}} \frac{A_{i+1} T_{i+1}^{n}-A_{i} T_{i}^{n}}{\Delta z}+\frac{w_{i}^{n}+\left|w_{i}^{n}\right|}{A_{i}} \frac{A_{i} T_{i}^{n}-A_{i-1} T_{i-1}^{n}}{\Delta z}\right)
$$

Substituting the calculated velocities from Equation (5), the vertical diffusivity $D_{i+1}^{n}$ can be evaluated using the discretised Equation (4). Thus, such 1D model can be applied to calculate the 
vertical velocity $w(t, z)$ and the diffusivity $D(t, z)$ for each layer $z$ and each time step $t$ by applying all VPS data, in particular temperature data and conductivity.

Subsequently, the Péclet number was calculated (Vyazmin et al., 2001):

$$
P e=\frac{L w}{D}
$$

with $L$ being the characteristic length. In unstratified flows, the characteristic length is the mean water depth; in a stratified lake, the length scale is the thickness of the selected epilimnion or hypolimnion layers. Whenever the Péclet number is higher than 1, advection can be considered dominant over diffusion; on the other hand, when it is less than 1, diffusion is more important than advection.

Moreover, since the lake circulation controls other transport processes in the lake, several lake indexes have been calculated to determine how stable the water column is (see e.g. Tundisi and Matsumura, 2011, for a list). These indexes include the Brunt-Väisälä Frequency (buoyancy frequency, $N$ ) and the Schmidt Stability Index, SSI, illustrated in Equations (8) and (9) respectively, as in Yu et al. (2010).

$$
\begin{aligned}
& N^{2}=\frac{-g \Delta \rho}{\rho \Delta z} \quad\left[s^{-2}\right] \\
& S S I=\frac{1}{A_{0}} \int_{z_{0}}^{z_{m}} A(z)\left(z-z_{g}\right)\left(\rho(z)-\rho_{g}\right) d z \quad\left[\frac{\mathrm{kg} \cdot \mathrm{m}}{\mathrm{m}^{2}}\right]
\end{aligned}
$$

where $g$ is the gravity force $\left[\mathrm{m} / \mathrm{s}^{2}\right] ; \rho$ is the water density $\left[\mathrm{kg} / \mathrm{m}^{3}\right] ; A_{o}$ is the surface area of the lake $\left[\mathrm{m}^{2}\right] ; z$ is the depth $[\mathrm{m}] ; z_{m}$ is the maximum depth $[\mathrm{m}] ; z_{0}$ is the water surface depth $[\mathrm{m}] ; A(z)$ is the lake horizontal area at depth $z\left[\mathrm{~m}^{2}\right] ; \rho(z)$ is the water density at depth $z\left[\mathrm{~kg} / \mathrm{m}^{3}\right] ; \rho_{g}$ is the density at depth $z_{g}\left[\mathrm{~kg} / \mathrm{m}^{3}\right] ; z_{g}$ is the depth to the centre of gravity of the stratified lake $[\mathrm{m}]$, calculated as in following:

$$
z_{g}=\frac{\int_{z_{0}}^{z_{m}} A(z) \rho(t, z) z d z}{\int_{z_{0}}^{z_{m}} A(z) \rho(t, z) d z}
$$


Figure 3 gives a graphical representation of most of the variables present in the previous equations.

The Brunt-Väisälä Frequency represents the angular frequency at which a vertically displaced parcel will oscillate within a statically stable environment. The Schmidt Stability Index, on the other hand, represents the amount of work to be done by the wind, or other sources of work (such as artificial destratifiers) to overcome thermal stratification, and it is intended to provide a number for the lake as a whole (Schmidt, 1928).

Ultimately, a one-dimensional analysis of internal waves was performed by plotting different isotherms over time; the higher the fluctuation over a small time scale (e.g. during one day), the stronger the internal waves. If strong internal waves are detected around the thermocline, this could lead to mixing processes between the nutrient-rich hypolimnion and the epilimnion. The period of the internal waves due to density differentials between the epilimnion and hypolimnion was calculated using the following equation as in Kanari (1975):

$$
\tau=2 l\left[\frac{\rho\left(h_{1}+h_{2}\right)}{\Delta \rho\left(g h_{1} h_{2}\right)}\right]^{1 / 2}
$$

where $\Delta \rho / \rho$ is the fractional density difference between the two layers, $h_{1}$ and $h_{2}$ the thicknesses of the layers, $g$ the gravity force and I the effective length of the lake $(2 \mathrm{~km})$.

Vertical waves velocities induced by internal waves was approximated by using the formula of Pernica et al. (2013):

$$
w=2 \pi \lambda f
$$

with $\lambda$ being the internal wave amplitude and $f$ its frequency.

\section{Results and Discussions}

\subsection{Inter-relationship of the parameters}


Table 1 summarizes the results of the pre-processing of the data, focusing on the factors affecting the water column temperature differential, defined in Equation (13):

$$
\frac{\Delta T_{w}(t)}{\Delta z(t)}=\frac{T_{w, s u r f}(t)-T_{w, b o t}(t)}{z_{r e s}(t)}
$$

where $T_{w, \text { surf }}(t)$ is the water temperature at the reservoir surface at time $t\left[{ }^{\circ} \mathrm{C}\right] ; T_{w, b o t}(t)$ is the water temperature at the bottom of the reservoir at time $t\left[{ }^{\circ} \mathrm{C}\right]$; and $z_{\text {res }}(t)$ is the depth of the reservoir at time $t[\mathrm{~m}] \cdot \frac{\Delta T_{w}(t)}{\Delta z(t)}$ can be considered a good indicator of water mixing, since it shows high values when the stratification is strong, but it goes to zero during mixing.

Specifically, Table 1 shows the results of the selected statistical tests, namely Jarque-Bera, Lilliefors, BC and BDS tests, and also the calculated correlation coefficients for the possible predictors of the water column temperature differential, optimized by the best lag and moving average. Firstly, it is possible to notice from the results of the aforementioned tests shown in Table 1 that all the analysed time series present complexities as they are typically nonlinear (as often can be expected for environmental time series), non-normal and bimodal in case of rainfall and inflow; the latter was expected for variables such as rain, whose values include a large amount of zeros, and a number of values substantially different from zero when there are significant precipitation events. Inflow is strictly related to the amount of rain; hence they follow the same bimodal behaviour. Variables such as air temperature or radiation, which follow a seasonal cycle with values gradually changing over time, did not have the same bimodal characteristics. The detected complexities highlight the importance of integrating the calculation of $R_{t, k, m, j, n}$ by Equation (1) with the analysis of the scatter plots in order to consider possible nonlinear relationships between variables. Figure 4 shows the scatter plots between $\frac{\Delta T_{w}(t)}{\Delta z(t)}$ and the possible predictors. It can be seen how neither linear nor nonlinear correlations are present between $\frac{\Delta T_{w}(t)}{\Delta z(t)}$ and rain, wind, inflow or outflow, thus indicating how their impact in triggering the full lake circulation is limited in Advancetown Lake. On the other hand, there are clear linear dependencies between values of air temperature or solar radiation and the water column temperature differential, thus indicating a 
strong relationship between water heating/cooling and mixing processes. These correlations improve further by considering the best lags and moving average spans indicated in Table 1.

In addition to the previous analysis, the relationships between the possible inputs and the strength of the thermocline have been calculated. The strength of the thermocline is defined as the maximum slope of the temperature profile, measured in ${ }^{\circ} \mathrm{C} / \mathrm{m}$. Following previous studies discussed in Kirillin (2002), a thermocline is present only if the thermal gradient of the layer is > $1^{\circ} \mathrm{C}$. The results show how the thermocline is expectedly much stronger in summer and disappears in winter. The maximum strength reached varies each year, but are predominately within the range of 1 to $1.5^{\circ} \mathrm{C} / \mathrm{m}$. The correlations found were similar to the ones of the analysis with $\frac{\Delta T_{w}(t)}{\Delta z(t)}$, however by considering the daily variation of the strength of the thermocline, it was possible to notice nonlinear correlations between this index and high rainfall events. In particular, the following relationship was shown to have a correlation coefficient of 0.48 at lag=0:

$$
\frac{\Delta}{\Delta t}\left(\frac{\Delta T_{w, t h}(t)}{\Delta z, t h(t)}\right)=-0.41 \cdot \ln \text { Rain }+1.51
$$

where $\frac{\Delta}{\Delta t}\left(\frac{\Delta T_{w, t h}(t)}{\Delta z_{, t h}(t)}\right)$ is the daily variation of the thermal gradient at the thermocline $\left[{ }^{\circ} \mathrm{C} /(\mathrm{m} \cdot\right.$ day $\left.)\right]$, and Rain $[\mathrm{mm}]$ represents high precipitation events (i.e. $>40 \mathrm{~mm} /$ day). Hence, for any high rainfall event that usually occurs in summer, there is an exponential drop in the strength of the thermocline and therefore of the stratification. In conclusion, this second type of analysis allows detecting the importance of variables such as rain to trigger turbulent events that may be able to reduce the lakes' thermal stability and cause a partial mix of the water column. Nevertheless, analysis of historical data showed that such events were not able to induce a full mix in the lake outside of the critical winter period when the thermocline is already weak.

\subsection{Lake mixing dynamics}

From the conclusions of the data analysis, it is clear how the thermal cycle, which affects the strength of stratification and thus the intensity of the mixing processes, is strictly related to the air 
temperature and to the solar radiation, even though sporadic events such heavy rainy days can diminish the thermal stability. Figure 5 shows the relationship between water temperature at different depths and air temperature, besides other parameters. First of all, it can be noticed how the waters of the hypolimnion and epilimnion have the same temperature during winter, when the lake circulation occurs, thus confirming that Advancetown Lake is a warm monomictic reservoir circulating every winter. During the rest of the year, the epilimnion is warmer, reaching a maximum temperature differential with the hypolimnion during summer. It seems that the relationship between water temperature and air temperature is different between the warming season and the cooling season; during the latter, the air temperature cycle clearly anticipates the surface water temperature cycle. Contrariwise, the figure shows how rainfall events are significant only during summer, when the stratification is at its peak, thus leading only to partial water mixings through high inflow events. This process could be numerically quantified through Equation (14) as shown previously. Similarly, the wind is not very relevant in triggering the mixing. In Figure $5(d)$, the values of the transformed wind is the wind speed component $(W)$ multiplied by the squared value of the fetch $(f)$ where they act, to take into account of the wind direction. Different combinations of wind and fetch (e.g. $w^{\star} f, w^{\star} f^{2}, w^{2} \star f, w^{2} f^{2}, \log (w) \star f$ and so on) were also tested, and the reported transformation $\left(w^{\star} f^{2}\right)$ yielded a slightly higher, despite still relatively low, correlation with water temperature than the other transformations. It can be seen how the wind is unable to accelerate the water mixing during the cooling season, which is rather a gradual process consisting of colder, denser surface water sinking downwards: thus, Advancetown Lake can be defined as "hydrologically deep", meaning that it is deep enough to prevent the wind action from destratifying the liquid mass (Straškraba et al., 1993). Only during the second week of August 2010, after a first mixing occurred, a number of very significant wind events were able to mix the whole water column again. Overall, the air temperature appears to be the dominant predictor.

A study of internal waves was performed through the analysis of different isotherms. In Figure 6, five isotherms located at around the depth of the thermocline during a period of two weeks in summer 2009 are represented. For this particular season, the internal wave period was calculated 
to be approximately 3 hours and the vertical velocity was $0.3 \mathrm{~mm} / \mathrm{s}$. It can be noticed how the amplitude of the waves is relatively small $(\lambda<1 \mathrm{~m})$, thus the vertical mixing in the metalimnion due to internal waves is typically limited.

Additionally, during very windy days such as on the 9 January 2009 (see Figure 6, wind speed > 6 $\mathrm{m} / \mathrm{s}$ for over 6 hours), it is shown how the wind has the power of creating a thicker surface mixed layer, pushing down the thermocline, which also becomes stronger (the $4^{\circ} \mathrm{C}$ differential was located within a 3-metre layer, but after the wind event the gradient was contained in a 1-metre layer only). Thus the wind can have a strong power in mixing and deepening the epilimnion. However, the deepening only affects a few metres of the lake's total depth of around 50m at the VPS location. The lakes' depth implies that a high amount of work is required to fully mix it in periods of strong density stratification, which cannot be displaced by the wind only.

As a further confirmation of the unlikelihood of summer wind events being able to trigger a lake circulation, the calculated SSI and Brunt-Väisälä Frequency are shown in Figure 7. The SSI figure shows that, because of the strong density gradient present during stratification, a huge amount of work would be required to cause a destratification. The required amount of work increased even further after the 2012 "Stage 3" dam raising completion due to the significant increase in the reservoir volume. As it can be seen from Figure 8, even though the strength of the stratification or the vertical thickness of the thermocline did not change significantly, the cross-sectional area $A(z)$ of the layers where the thermocline is present became bigger, since they are situated at higher elevations; hence, by applying the formula for SSI, the index value increases, as well as the stability of the water column. With the approaching of winter, the density gradient becomes weaker and weaker, thus enabling weaker and weaker wind events to mix the whole water column. However, the mixings were recorded only when $\mathrm{SSI} \cong 0$, meaning that even in extreme water column instability situations the applied wind stress was not strong enough to complete the mixing. Similar results were achieved by studying the Brunt-Väisälä Frequency, with the amount of work needed to break down the density gradient gradually decreasing during the cooling season. 
In Figure 9, the surface vertical velocity $w_{S}$ was calculated using $\frac{\partial \eta}{\partial t}+w_{S}(t)=0$ and plotted with the water column height and the rainfall time series. It can be noticed how there are sporadic important advection phenomena during heavy rainfall events during summer (e.g. February 2010 and 2012, January 2013), due to also the increased inflow, which is implicitly accounted by the water column height. However, it must be emphasized that the average vertical velocity values in the water column over the study period are in the order of $10^{-9} \mathrm{~m} / \mathrm{s}$. However, Figure 10 shows that the diffusivity values are in the range of $10^{-5}-10^{-3} \mathrm{~m}^{2} / \mathrm{s}$. The calculated Peclet number has confirmed that the diffusion mixing is the dominant process in the Advanced Lake. The convection term in Equation (4) can be ignored.

Interestingly, through the application of the developed one-dimensional model it is possible to localize the onset of the winter turnover events; this is clear from Figure 11, where vectors representing diffusivities at different depths are plotted along with the water column temperature differential. As an example, it is possible to notice, at the end of May 2011, how suddenly high diffusion processes are present in the whole water column, rather than in the first $10-15 \mathrm{~m}$ only. During the same time steps, the water column temperature differential reached its minimum values, and a full lake circulation began.

\section{$\underline{3.3 \text { Effect of volume and extreme events in mixing processes }}$}

Figures 12(a) and (b) show respectively the dissolved oxygen concentration and the water temperature in Advancetown Lake for the period from May to September 2013, which included the 2013 winter turnover; it can be noticed how the volume of the dam increased in February 2013 (see Figure 2) to its new full capacity.

The higher volume implies a higher amount of work needed to mix the whole water column, as it was shown through the SSI calculation. As a consequence of this, and of higher than normal winter temperatures (average minimum July temperatures and maximum August temperatures $2^{\circ} \mathrm{C}$ higher than 1992-2012 average values recorded in Gold Coast Seaway by the BoM), the figures 
show that only a partial mixing occurred. The water temperature of the water column was uniform for only a few nights in June, when the surface temperature typically drops an extra $0.5{ }^{\circ} \mathrm{C}$ compared to daytime. This might have enabled short-term mixings with the lower layers, with the colder surface waters sinking down towards deeper layers. However, because of the calculated velocities, few cold nights do not provide sufficient time for a full circulation to occur. Because the cold nights were followed by warmer-than-usual days, a weak stratification constantly took place during daytime, thus interrupting the transport processes occurring between surface and deeper layers. Usually, the whole column has the same temperature for at least one month, thus providing enough time for a full mixing. Moreover, through the dissolved oxygen concentrations it can be seen that there was a gradual mixing downwards, but it did not affect waters deeper than 30 metres. An increase in oxygen level in July in the very bottom waters was recorded, most likely due to the intrusion of well-oxygenated water coming from the shallower littoral areas. Figure 13 shows typical summer-winter vertical profiles for the upgraded dam; it can be noticed how in winter a very weak stratification persisted $\left(0.8^{\circ} \mathrm{C}\right.$ between top and bottom waters), and that was enough to limit the water mixing. Evidence of this process occurring is illustrated by the winter dissolved oxygen profile, which shows unexpected heterogeneous concentrations though the water column, while typically, if a full turnover occurs, almost homogenous concentrations from top to bottom is to be expected. Local negative peaks (at $6 \mathrm{~m}$ in summer and $13 \mathrm{~m}$ in winter as shown in Figure 13(b)) are most likely caused by oxygen intrusions coming from the river.

\section{Conclusions}

A comprehensive analysis of the available field data for Advancetown Lake was performed. A onedimensional model determining the relative contribution of diffusion and advection was implemented, as well as an analysis of internal waves and the calculation of indices describing the mixing of the waters in the reservoir.

The main conclusions of the research study are the following: 
- Advancetown Lake, prior the recent upgrade, could have been classified as a warm monomictic lake, with one full circulation occurring during winter encompassing the whole water column, and a propensity for partial mixings after summer turbulent events.

- The driving forces of the mixing processes are substantially different between summer and winter. In summer, rainfall, river inflow and wind can trigger partial water mixings. High inflow events create partial water mixings at the depth of the intrusions, heavy rain exponentially weakens the thermocline, and strong wind events can mix and deepen the epilimnion. However, the winter full lake circulation is driven by thermal instability of the water column only, since no high rainfall events occur during this dry season. Furthermore, wind does not appear to play a role in triggering the lake circulation; this is because Advancetown Lake can be classified as "hydrologically deep", requiring significant work by forces such as wind to mix such a body of water, when compared to shallower lakes.

- Because of the high correlation between lagged, smoothed values of air temperature, solar radiation and water temperature, there is potential for predicting the strength of thermal stratification up to 10 days ahead with a multivariate statistical model. Reliable air temperature forecasts, along with the use of a seasonal model were shown to further improve correlation coefficients. Moreover, it was possible to extract some nonlinear correlations between sporadic local drops in the thermocline strength and heavy rainfall events. Thus, by having reliable air temperature and rainfall forecasts, it would be possible to predict the strength of the thermal stratification for Advancetown Lake with a reasonable accuracy.

- The vertical mixing processes are driven mainly by diffusion, while advection plays only a minor, negligible role. The diffusion is higher during the winter circulation, while it is at its lowest during summer, because of the stability induced by a strong thermal stratification.

- The implemented one-dimensional model can be applied in real time to calculate diffusivities any time a new vertical profile of temperature and conductivity has been collected by the VPS, thus adding value to this tool and enabling better understandings of the mixing processes affecting the lake at any given time of the year. 
- Internal waves located at the thermocline tended to be faster $(0.3 \mathrm{~mm} / \mathrm{s})$ than velocities induced by vertical mixing processes; however, their amplitude is too limited to enable considerable mixing between the upper and lower metalimnion.

- During 2013, which is post the dam upgrade, the higher volume increased the level of resistance to a full lake circulation as demonstrated by an increase in SSI values; this characteristic was further compounded by a warmer-than-usual winter during that circulation period. As a result, only a partial mixing was evident in the top 30 metres of the reservoir. Hence, in 2013, Advancetown Lake behaved more like a meromictic lake. Future work analysing the 2014 circulation processes will seek to confirm whether the dam upgrade has predominately transitioned the lake characteristics from a monomictic to a meromictic regime.

With the continuous monitoring of the features of the reservoir through the VPS, the analysis of the next winter circulation events will be of great interest. Meromixis leads to the formation of a constantly anoxic deep layer called monimolimnion, which contains an increased level of nutrients (Boehrer et al., 2009). In case of cold weather extremes leading to monimolimnetic overturns, those nutrients will reach the top, oxygenated layer called mixolimnion, where the water is usually drawn and redirected to the treatment plant, thus implying several issues for the water supplier. Two main changes brought to meromixis in 2013: the increased reservoir's volume, which augmented the resistance to water mixing, and the warmer winter, which implied warmer waters and thus more work required for breaking down the thermal stratification. If the warmer winter had been the main factor, then average winter temperatures would lead to a full circulation again in 2014, regardless of the higher volume; on the other hand, if the increased volume had been the main factor, then most likely Advancetown Lake will be predominately exhibit meromictic characteristics in the future.

\section{Implications and Future Research Directions}

Having a good understanding of the physical properties of a water storage reservoir is pertinent for dam and water treatment plant operators. Also, changes to the catchment area and reservoir dimensions, as in the case with the recent Advancetown Lake upgrade, have implications on the 
future characteristics of the lake and need to be carefully monitored and studied in advance of any unexpected nutrient build-up combined with different circulation events that may result and have detrimental effects to the water quality drawn from the reservoir for potable use purposes. This study, through the use of the high-frequency VPS data, enabled a deeper understanding of the processes related to mixing events in different seasons in Advancetown Lake. In 2014, further analysis will be undertaken to understand whether recent changes in lake circulation characteristics will be sustained or the lake reverts back to its historical monomictic state.

For Advancetown Lake and its supplied Gold Coast City region, there are a number of aspects that need to be carefully monitored and modelled in the future to ensure that dam operators can proactively address and mitigate future potential problems originating from the following:

- The expected increase in average temperatures could lead to warmer winters and constant meromixis, with very high concentrations of nutrients stored in the monimolimnion.

- Climate change will also bring to more frequent drastic events such as floods and droughts. In the case of drought, the volume of the reservoir will decrease, thus making a full circulation more likely; in the case of extreme floods, then rain and extremely high inflow events might play a more important role and increase the mixed layer depth during the partial mixing events than in the past.

- The expected rapidly increasing population in the Gold Coast City region will result in an increased demand for potable water, thus potentially leading to a decreased average volume in the dam at any point in time.

Further studies are required to better assess the relative importance of reservoir volume and air temperature in limiting the lake circulation processes, and to link these features with climate change and urban development scenarios. Such scenario analysis, supported by available empirical data, will enable predictions of the future likelihood of Advancetown Lake exhibiting either monomixis or meromixis characteristics in a particular year.

\section{Acknowledgments}


The authors acknowledge Seqwater and Griffith University for providing the financial and technical support necessary to make this research study possible.

\section{References}

ABESSER, C., ROBINSON, R. 2010. Mobilization of iron and manganese from sediments of a Scottish Upland reservoir. J. of Limnol., 69 (1), 42-53.

AKITOMO, K., KUROGI, M., KUMAGAI, M. 2004. Numerical study of a thermally induced gyre system in Lake Biwa. Limnol., 5, 103-114.

AKITOMO, K., TANAKA, K., KUMAGAI, M., JIAO, C. 2009. Annual cycle of circulations in Lake Biwa, part 1: model validation. Limnol., 10, 105-118.

AMERICAN SOCIETY OF CIVIL ENGINEERS. 1996. Hydrology Handbook, Second ed.

ARMENGOL, J., CAPUTO, L., COMERMA, M., FEIJOÓ, C., GARCÍA, J. C., MARCÉ, R., NAVARRO, E., ORDOÑEZ, J. 2003. Sau reservoir's light climate: relationships between Secchi depth and light extinction coefficient. Limnetica, 22(1-2), 195-210.

BEDNARZ, T. P., LEI, C., PATTERSON, J. C. 2011. A numerical study of unsteady natural convection induced by iso-flux surface cooling in a reservoir model. Int. J. of Heat and Mass Transf. 52, 56-66.

BERTONI, R. 2011. Limnology or rivers and lakes. in Limnology, [Ed. Brij Gobal], in Encyclopedia of Life Support Systems (EOLSS), Developed under the Auspices of the UNESCO, EolsS Publishers, Oxford, UK

BOEHRER, B., DIETZ, S., VON ROHDEN, C., KIWEL, U., JÖHNK, K. D., NAUJOKS, S., ILMBERGER, J., LESSMANN, D. 2009. Double-diffusive deep water circulation in an ironmeromictic lake. Geochemistry, Geophysics, Geosystems, 10(6).

BROCK, W. A., SCHEINKMAN, J., DECHERT, W., LeBARON, B. 1996. A test for independence based on the correlation dimension. Econometric Reviews, 15(3), 197-235.

COURANT, R., FRIEDRICHS, K., LEWY, H. (March 1967) [1928]. On the partial difference equations of mathematical physics. IBM J. of Research and Development 11(2), 215-234.

DODDS, W. K. 2002. Freshwater ecology. Concepts and environmental applications. Academic Press Inc, Oxford. 
ELÇI, Ş. 2008. Effects of thermal stratification and mixing on reservoir water quality. Limnol. 9, 135-142.

ESTEVES, F.A. 1998. Foundations of Limnology. (In Portuguese). Interciência, Rio de Janeiro.

FISHER, M. M., REDDY, K. R, THOMAS JAMES, R. 2005. Internal nutrient loads from sediments in a shallow, subtropical lake. Lake and reserv. management, 21(3), 338-349.

GAL, G, IMBERGER, J, ZOHARY, T, ANTENUCCI, J. P, ANIS, A, \& ROSENBERG, T. 2003. Simulating the thermal dynamics of Lake Kinneret. Ecol. Model. , 162, 69-86.

HAN, B.P., ARMENGOL, J., GARCIA, J.C., COMERMA, M., ROURA, M., DOLZ, J., STRASKRABA, M. 2000. The thermal structure of Sau Reservoir (NE, Spain): a simulation approach. Ecol. Model., 125, 109-122.

HELFER, F., ZHANG, H., LEMCKERT, C. 2011. Modelling of lake mixing induced by air-bubble plumes and the effects on evaporation. J. of Hydrol., 406, 182-198.

HULTH, S., ALLER, R.C., GILBERT, F. 1999. Coupled anoxic nitrification/manganese reduction in marine sediments. Geochim. Cosmochim. Ac., 63, 49-66.

IMBERGER, J., PATTERSON, J.C. 1981. A dynamic reservoir simulation model-DYRESM:5, In: "Transport Models for Inland and Coastal Waters." H.B. Fischer (ed). Academic Press, New York, pp. 310-361.

JARQUE, C. M., BERA, A. K. 1987. A test for normality of observations and regression residuals. Int. Statistical Rev., 55 (2), 163-172.

KANARI, S. 1975. The long-term period internal waves in Lake Biwa. Limnol. and Oceanogr., 20(4), 544-553.

KINDLE, E. M. 1929. A comparative study of different types of thermal stratification in lakes and their influence on the formation of marl. The J. of Geology, 37(2), 150-157.

KIRILLIN, G. 2002. Modeling of the vertical heat exchange in shallow lakes. Dissertation. Matematisch-Naturwissenschaftliche Fakultät II der Humbolt-Universität zu, Berlin, 104 pp

KITAZAWA, D., YANG, J. 2012. Numerical analysis of water circulation and thermohaline structures in the Caspian Sea. J. Mar. Sci. Technol., 17, 168-180. 
LILLIEFORS, H. 1967. On the Kolmogorov-Smirnov test for normality with mean and variance unknown. J. of the American Statistical Association, 62, 399-402.

MILLERO, F. J., POISSON, A. 1981. International one-atmosphere equation of state of seawater. Deep-Sea Res., 28, 625-629.

MOHAN, H., BURChARDT, P., WILlHite, G. P., REYNOLDS, R. R., JENSEN, M. 1996. Evaluating waterflood potential in a morrow sandstone reservoir. Paper presented at SPE/DOE Improved Oil Recovery Symposium, Tulsa, Oklahoma, 21/24 April 1996.

NÜRNBERG, G. K. 1988. A simple model for predicting the date of fall turnover in thermally stratified lakes. Limnol. and Oceanogr., 33, 1190-1195.

PERNICA, P., WELLS, M. G., SPRULES W. G. 2013. Internal waves and mixing in the epilimnion of a lake affects spatial patterns of zooplankton in a body-size dependent manner. Limnol. and Oceanogr.: Fluids and Environments, 3, 279-294

QUIRING, S. 2010. Albedo. In WARF, B. Encyclopedia of geography. Thousand Oaks, CA: SAGE Publications, Inc., pp. 66-67.

SOCOLOFSKY, S.A., JIRKA, H. 2004. Mixing in lakes and reservoirs. lecture notes available at https://ceprofs.civil.tamu.edu/kchang/ocen689/ocen689ch9.pdf (accessed 1/4/2014).

STRAŠKRABA, M., TUNDISI, J. G., DUNCAN, A. 1993. State-of-the-art of reservoir limnology and water quality management. In: STRAŠKRABA M., TUNDISI, J. G., DUNCAN, A. (eds), Comparative Reservoir Limnology and Water Quality Management. Dev. in Hydrobiol. ser., 77, 213-288.

TUAN, N. V., HAMAGAMI, K., MORI, K., HIRAI, Y. 2009. Mixing by wind-induced flow and thermal convection in a small, shallow and stratified lake. Paddy Water Environ., 7, 83-93.

TUNDISI, J. S., MATSUMURA, T. 2011. Limnology. Taylor and Francis Group, LLC.

VYAZMIN, A. V., KAZENIN, D. A., POLYANIN, A. D., KUTEPOV, A. M. 2001. Hydrodynamics, Mass and Heat Transfer in Chemical Engineering. CRC Press.

YU, H., TSUNO, H., HIDAKA, T., JIAO, C. 2010. Chemical and thermal stratification in lakes. Limnol., 11, pp. 251-257. 
ZAW, M., CHISWELL, B. 1999. Iron and manganese dynamics in lake water. Wat. Res., 33(8), 1900-1910.

ZHANG, H.,. CHAN, E. S. 2003. Modeling of the turbulence in the water column under breaking wind waves. Journal of Oceanography, Vol. 59, No. 3, 331-341. 
Table 1: Correlation coefficients between water temperature differential and possible predictors, at the best lag and best moving average span.

\begin{tabular}{|c|c|c|c|c|c|c|c|c|}
\hline \multirow{3}{*}{ Main predictors } & \multicolumn{4}{|c|}{ Statistical analysis } & \multicolumn{4}{|c|}{ Relevance in prediction } \\
\hline & \multirow{2}{*}{$\begin{array}{l}\text { JB } \\
\text { test }\end{array}$} & \multirow{2}{*}{$\begin{array}{l}\text { Lilliefors } \\
\text { test }\end{array}$} & \multirow{2}{*}{ BC } & \multirow{2}{*}{ BDS } & \multirow{2}{*}{ Literature } & \multicolumn{3}{|c|}{ Regression analysis } \\
\hline & & & & & & Best $R$ & $\begin{array}{c}\text { Lag } \\
\text { (days) }\end{array}$ & $\begin{array}{c}\text { MA } \\
\text { (days) }\end{array}$ \\
\hline Solar radiation & $\mathrm{F}$ & $\mathrm{F}$ & 0.40 & 14.8 & $\mathrm{H}$ & 0.88 & 21 & 14 \\
\hline Wind & $\mathrm{F}$ & $\mathrm{F}$ & 0.49 & 16.8 & $\mathrm{H}$ & 0.07 & 0 & 1 \\
\hline Air temperature & $\mathrm{F}$ & $\mathrm{F}$ & 0.54 & 6 & $\mathrm{H}$ & 0.91 & 7 & 7 \\
\hline Rain & $\mathrm{F}$ & $\mathrm{F}$ & 0.61 & 5.4 & M & 0.07 & 0 & 1 \\
\hline Inflow & $\mathrm{F}$ & $\mathrm{F}$ & 0.76 & 15.3 & M & 0.04 & 0 & 1 \\
\hline Outflow & $\mathrm{F}$ & $\mathrm{F}$ & 0.47 & 7.5 & M & 0.01 & 0 & 1 \\
\hline
\end{tabular}

$\mathrm{F}=$ False (normality assumption false)

$M A=$ Moving average span

BC $>0.555=$ Bimodality (BC=Bimodality Coefficient)

BDS $>1.96=$ Non linear dependencies (BDS statistics from the BDS test)

$\mathrm{H}=$ high; $\mathrm{M}=$ medium; $\mathrm{L}=$ low 


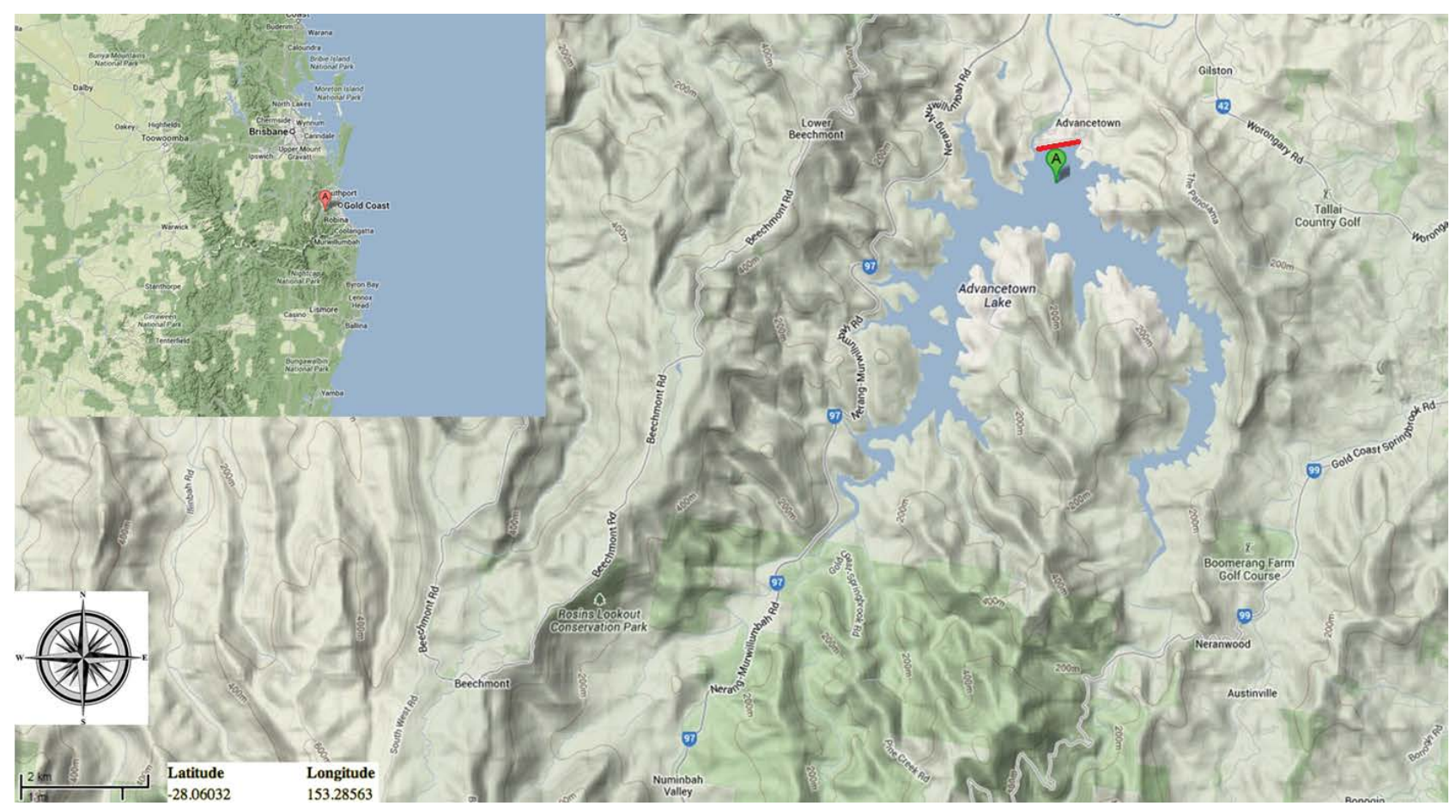

Figure 1. Advancetown Lake map; A is VPS location, red line is the dam wall location 


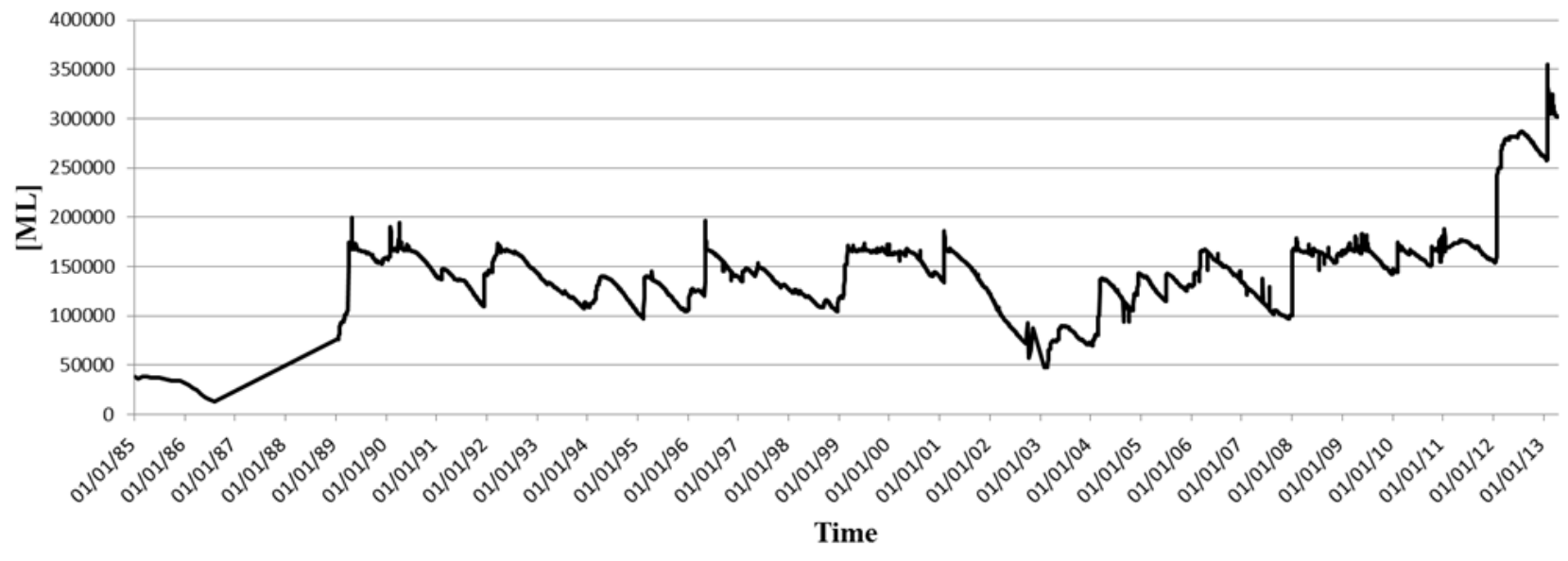

Figure 2: The time series of dam volume in Advancetown Lake volume from 1986 to 2013. 


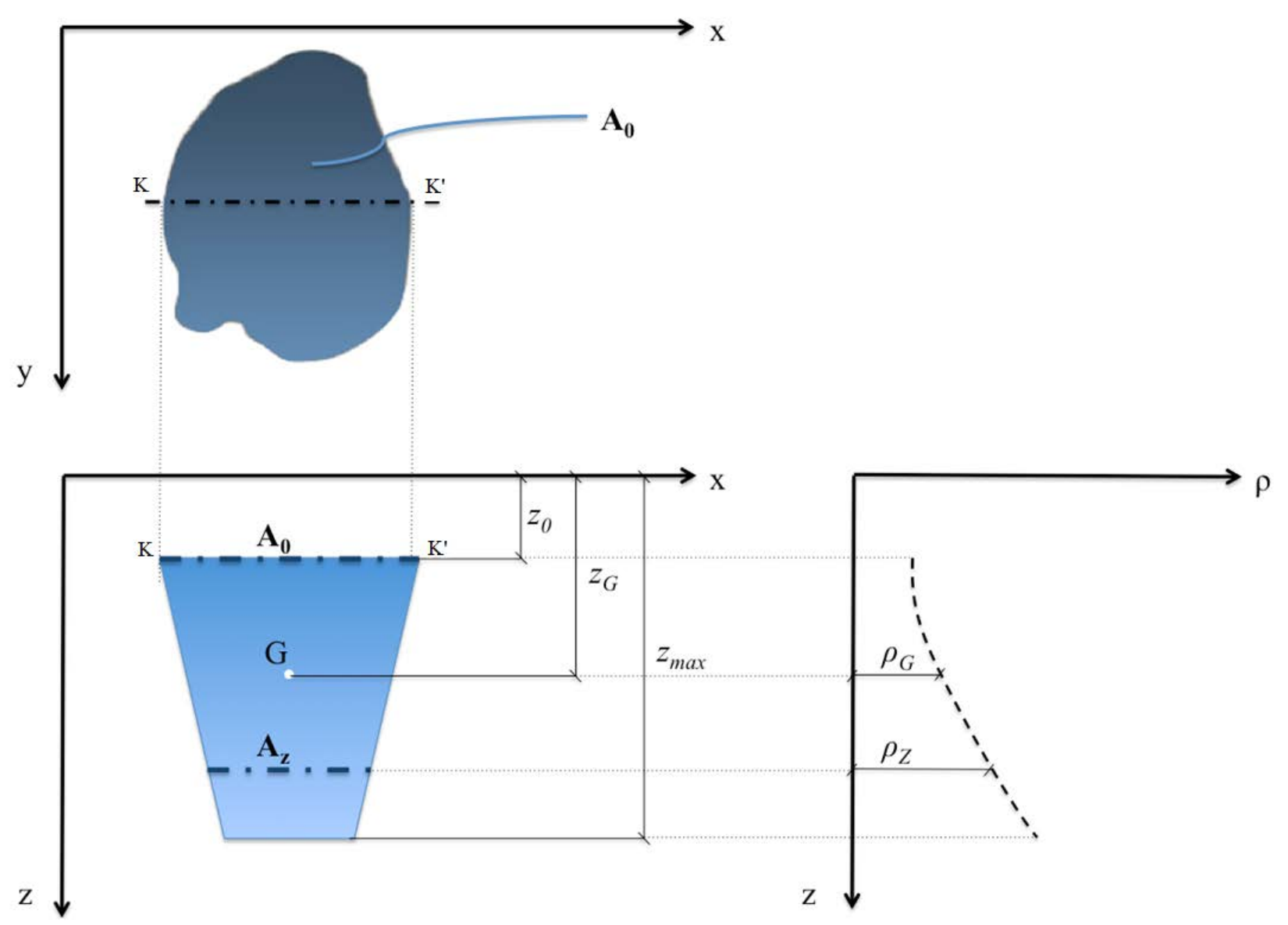

Figure 3: Schematic diagram of a lake, including a density vertical profile 

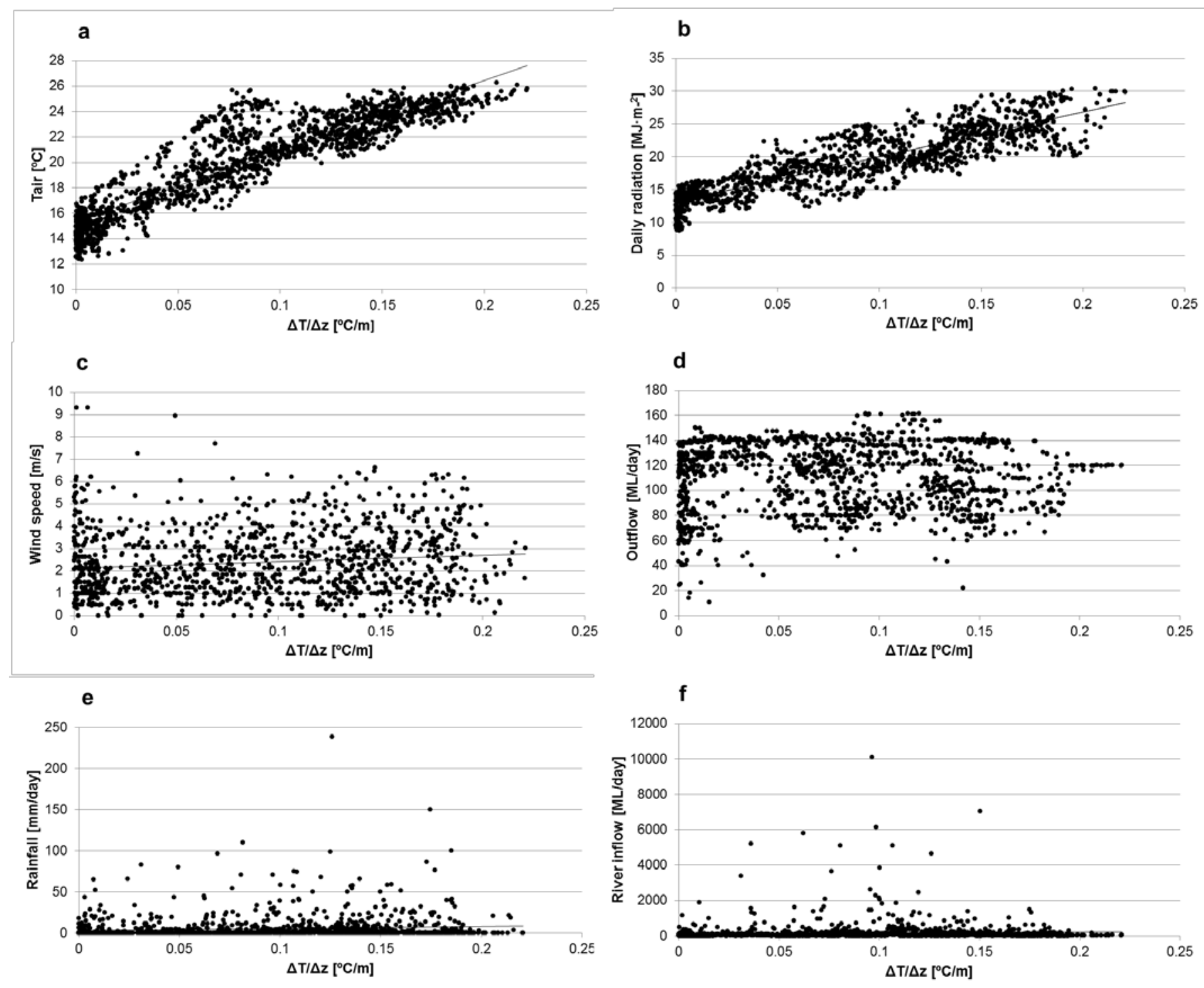

Figure 4: Scatter plots of vertical water temperature gradient and most likely predictors ((a): air temperature; (b): solar radiation; (c): wind; (d): outflow; (e): rainfall; (f): river inflow). 

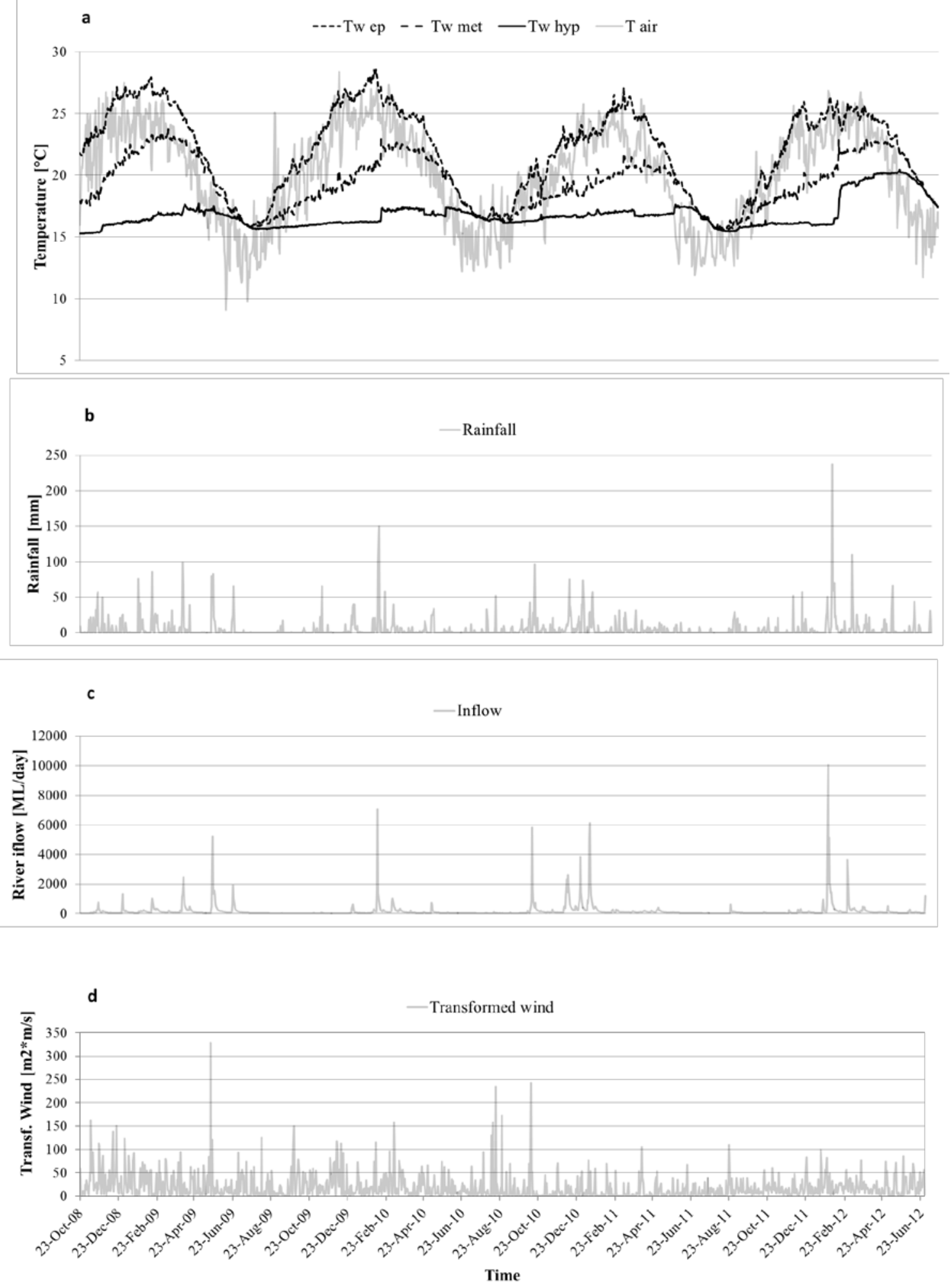

Figure 5: The time series of various parameters in Advancetown Lake from 2008-2012: (a) air temperature and depth average water temperatures (0-6m, 6-12m, 12-24m); (b) rainfall; (c) inflow; and (d) transformed wind $=$ wind $\cdot$ fetch $^{2}$ 


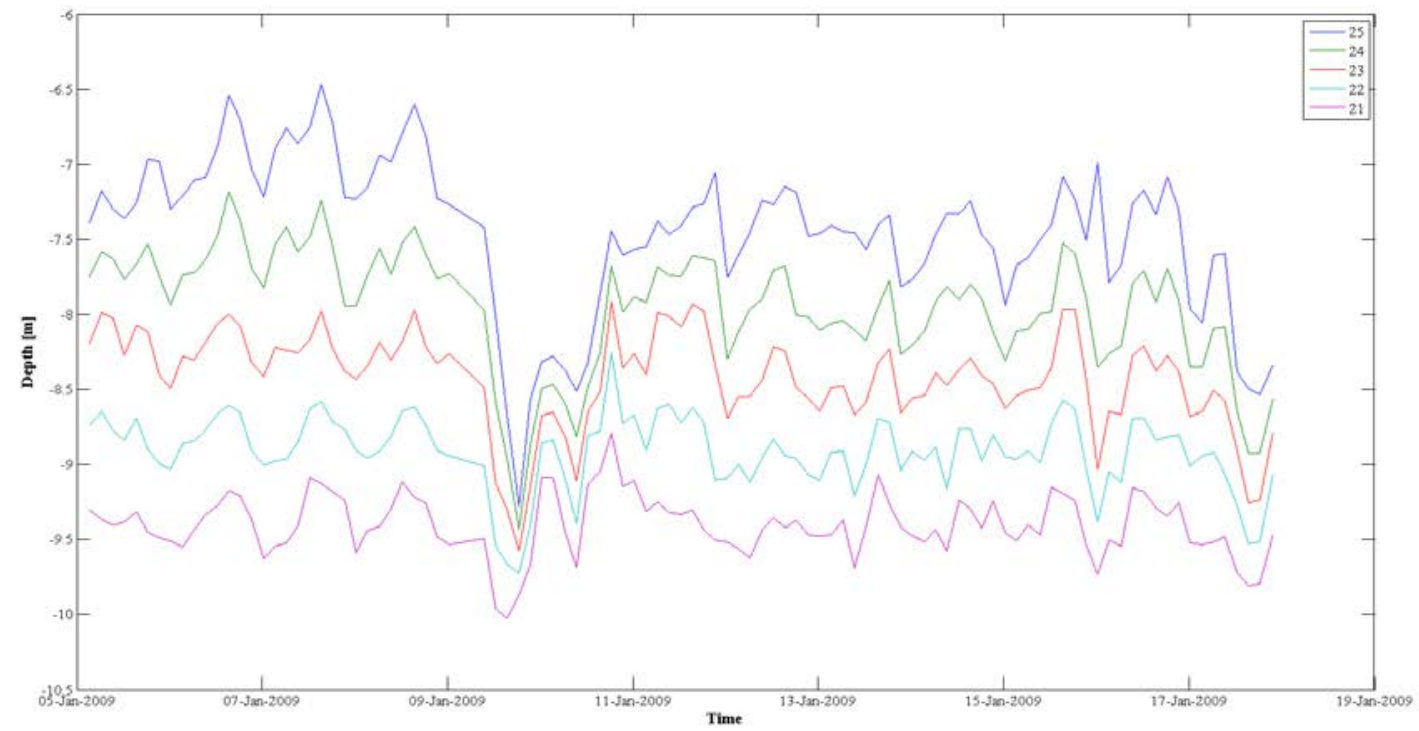

Figure 6: Isotherms analysis for Advancetown Lake between 5th and 18th January 2009. 


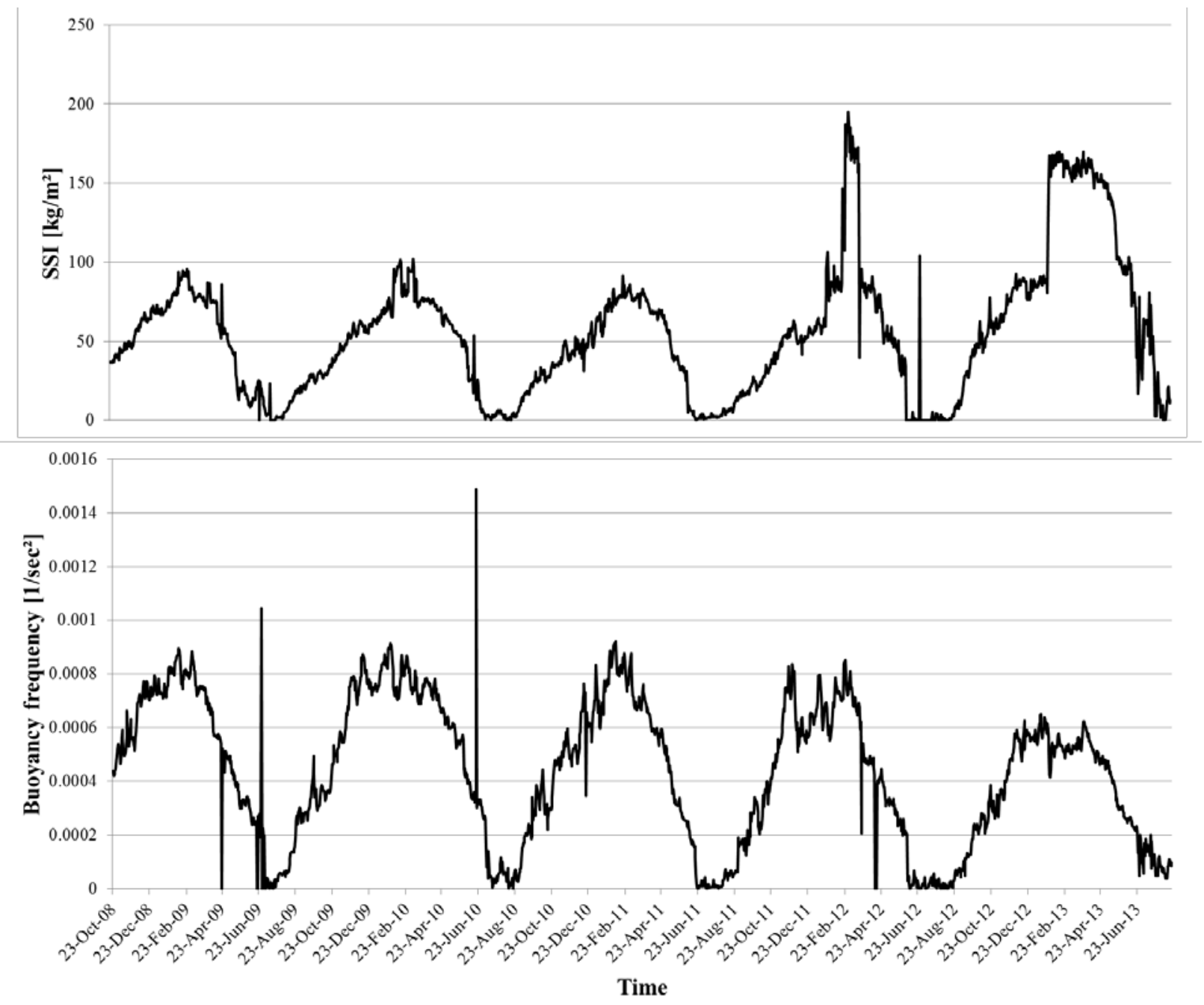

Figure 7: Schmidt Stability Index and buoyancy frequency calculated at the surface for Advancetown Lake for Advancetown Lake between October 2008 and June 2013. Local peaks/drops in buoyancy frequency due to sporadic critical salinity values in certain layers. 


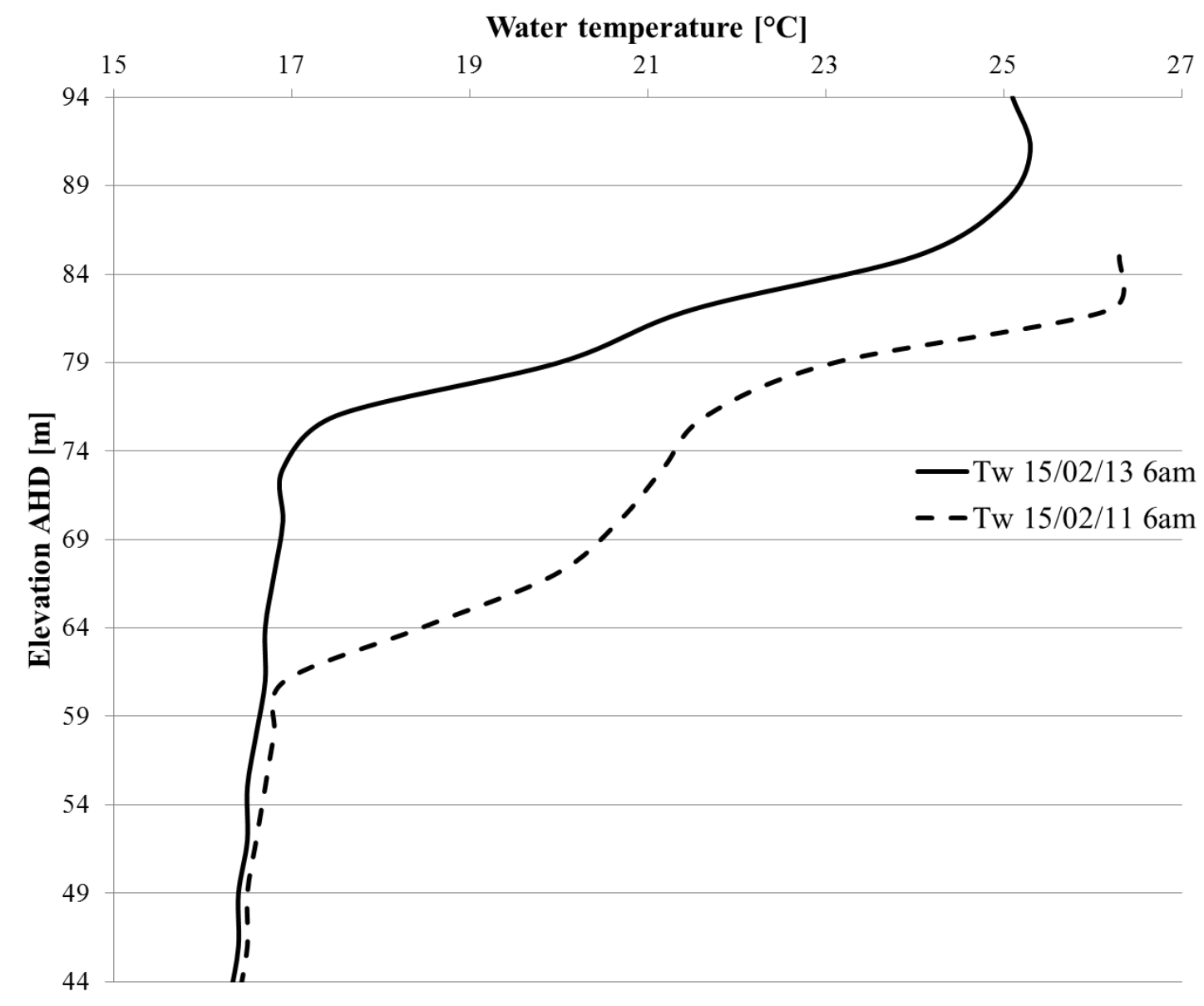

Figure 8: Summer water temperature profiles before/after dam upgrade, Advancetown Lake 


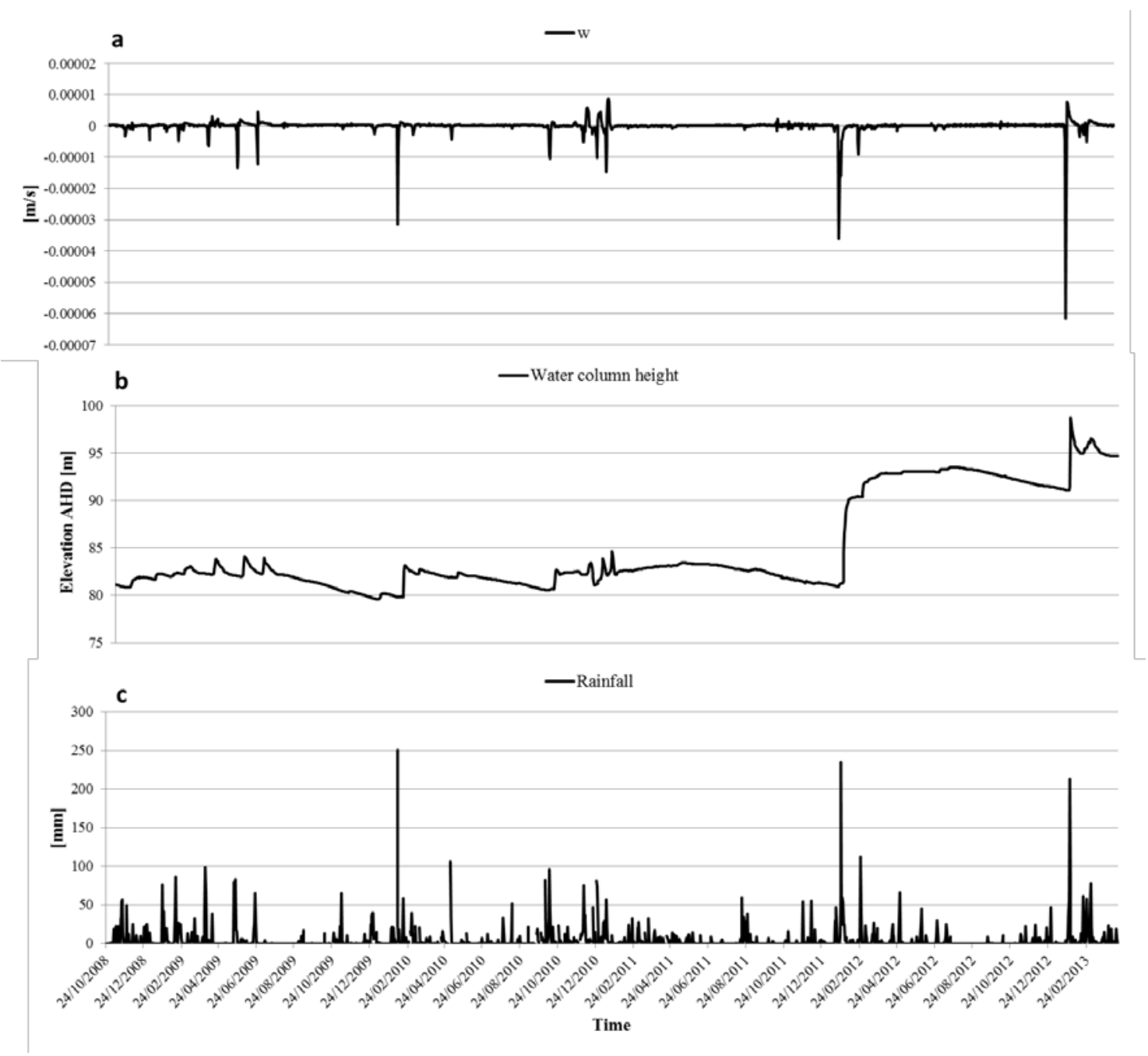

Figure 9: Time series of calculated (a) vertical surface velocities, (b) water column height and (c) rainfall in Advancetown Lake, 2008-2013. 


\section{$\mathrm{D}\left[\mathrm{m}^{2} / \mathrm{s}\right]$}

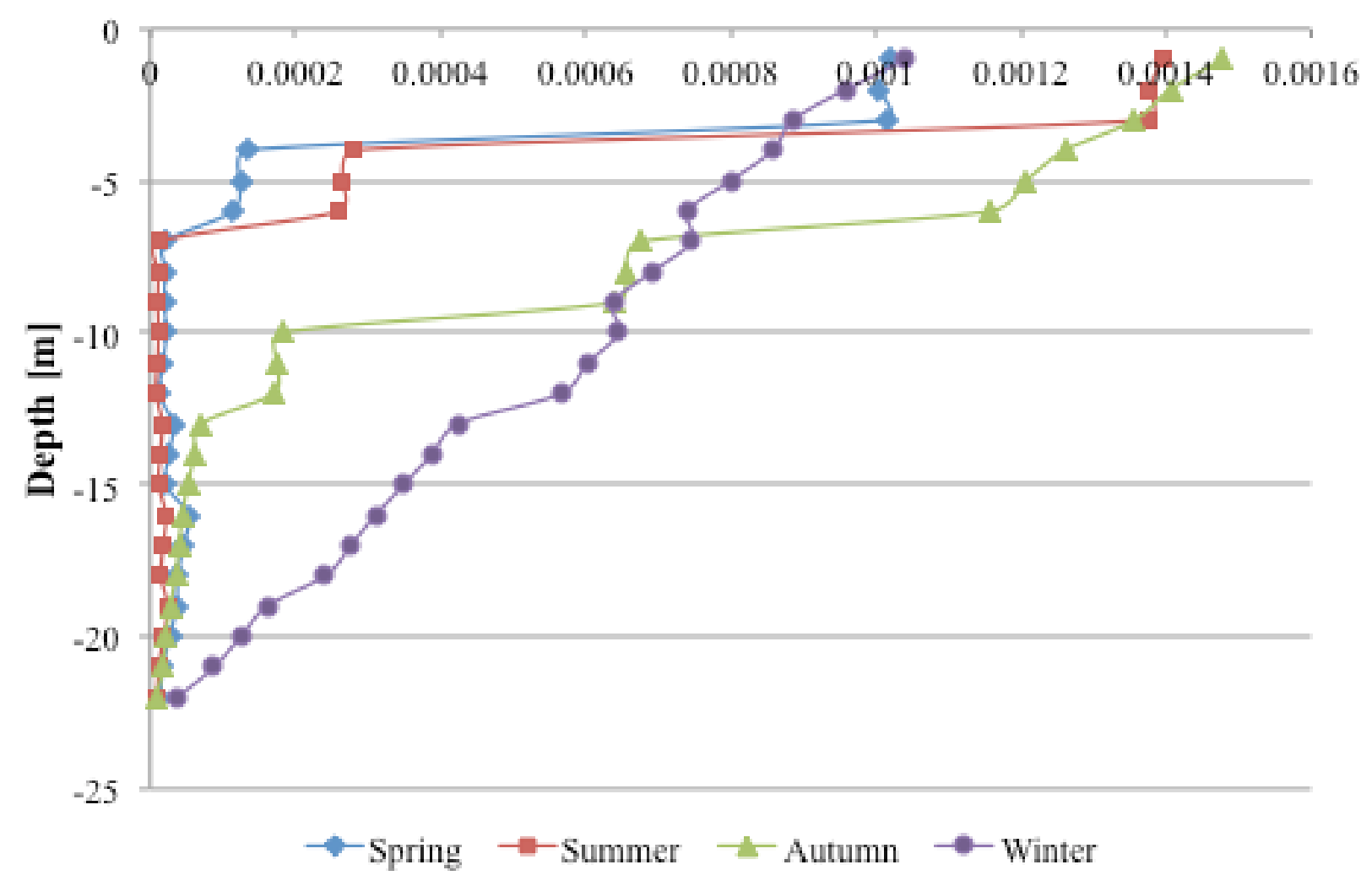

Figure 10: Averaged seasonal profiles of vertical diffusivities. 

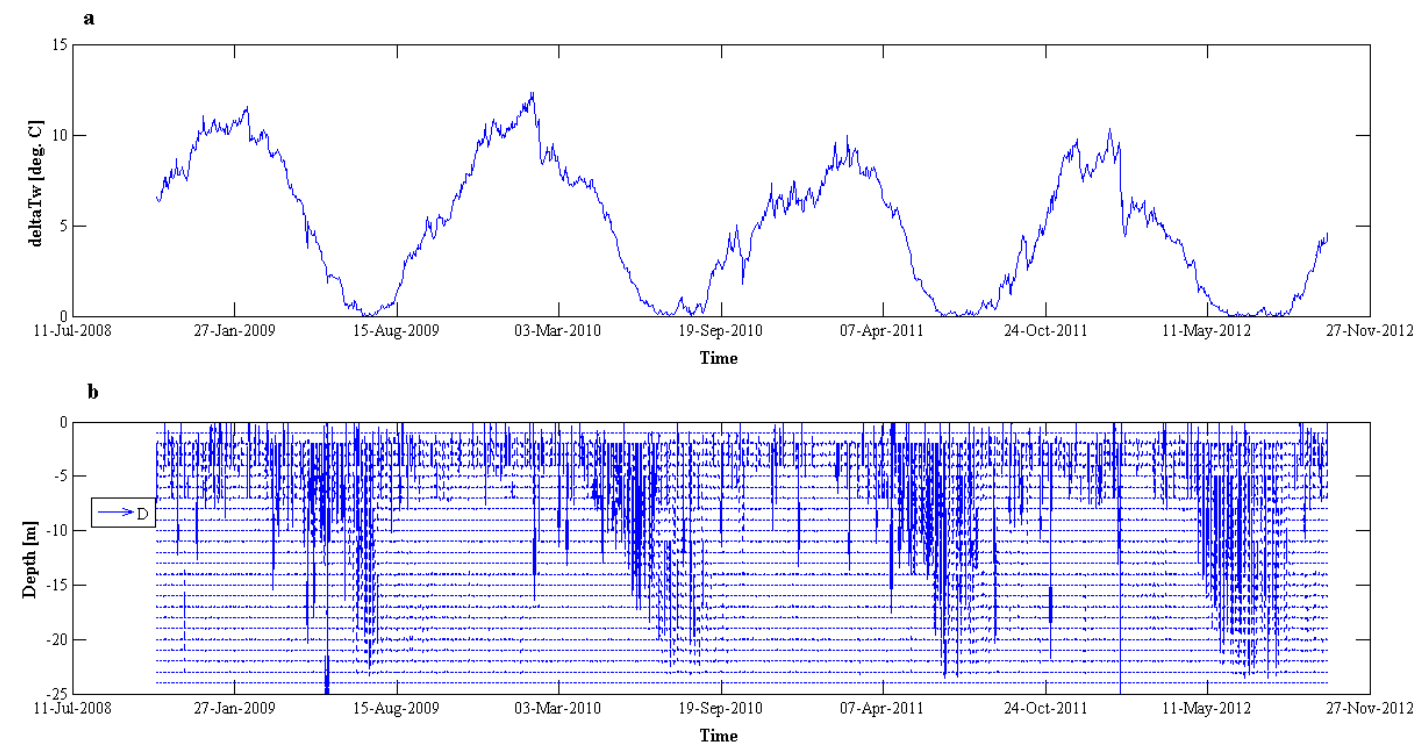

Figure 11: Time series of (a) column temperature differential, (b) vector plot diffusivity coefficients for the top 23m from the surface in Advancetown Lake, 2008-2012. 

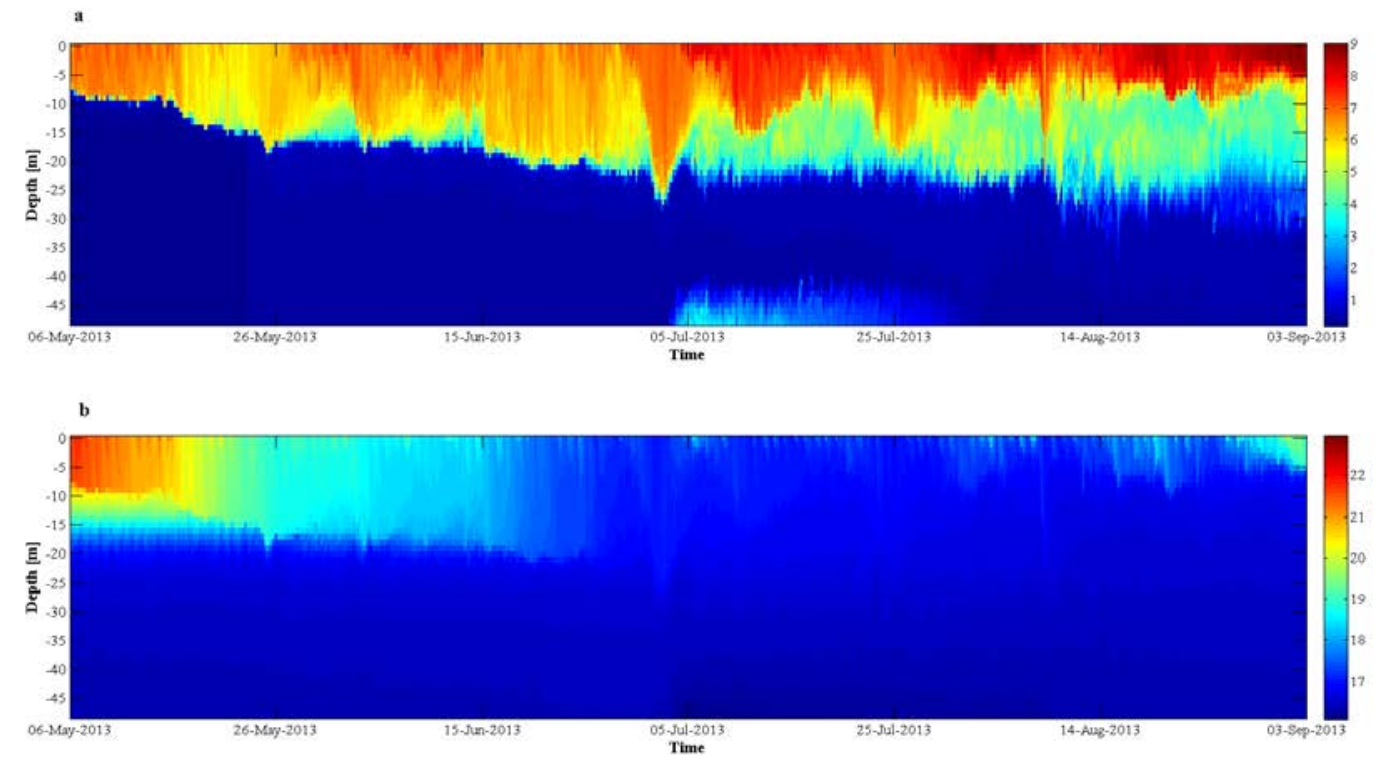

Figure 12: (a) Dissolved oxygen $(\mathrm{mg} / \mathrm{L})$ and $(\mathrm{b})$ water temperature $\left({ }^{\circ} \mathrm{C}\right)$ for Advancetown Lake between May and September 2013 (3-hours frequency; 0 to 48 metres depth). 

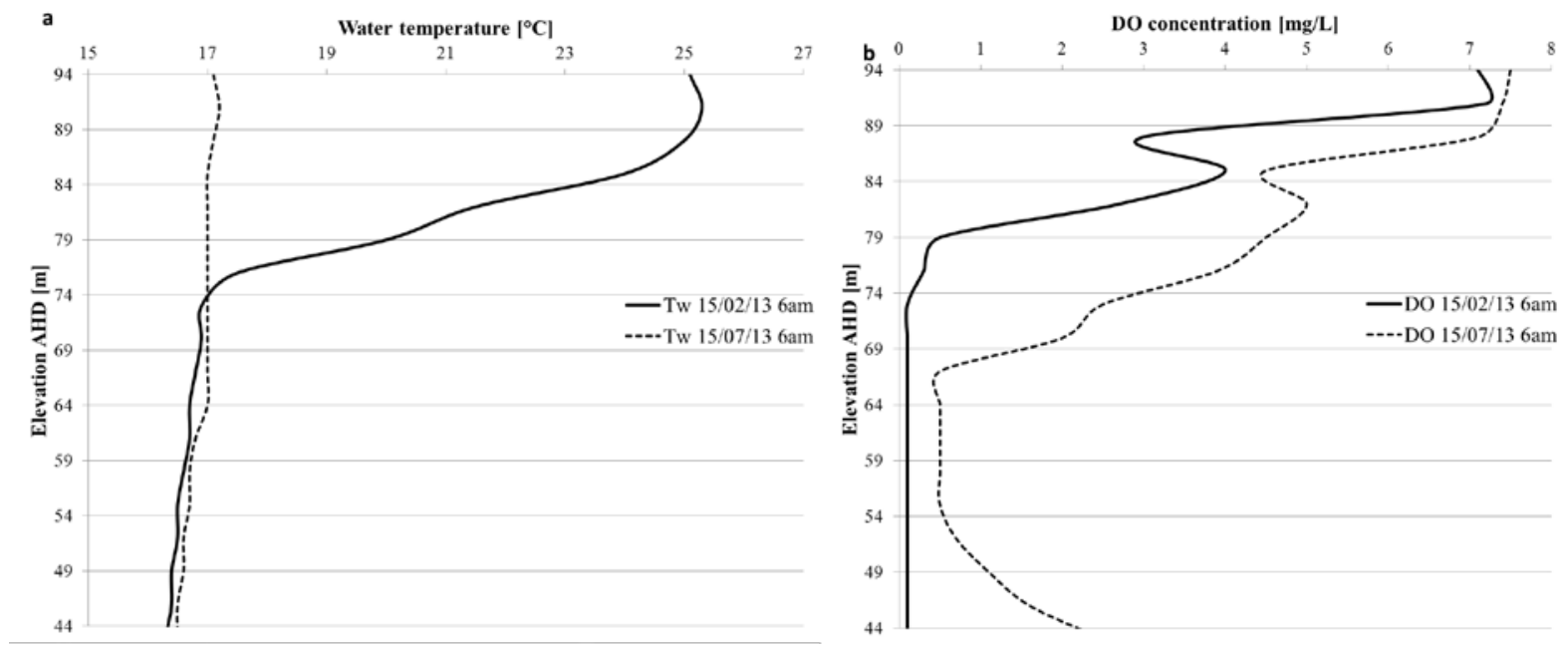

Figure 13: Typical summer and winter (a) water temperature $\left({ }^{\circ} \mathrm{C}\right)$ and $(\mathrm{b})$ dissolved oxygen (1mg/L) profiles for Advancetown Lake in 2013 (post dam upgrade). 